\title{
Serological tests fail to discriminate dogs with visceral leishmaniasis that transmit Leishmania infantum to the vector Lutzomyia longipalpis
}

\author{
Ivete Lopes de Mendonça[1], Joilson Ferreira Batista ${ }^{[1]}$, Guilherme Loureiro Werneck ${ }^{[2]}$, \\ Maria Regiane Araújo Soares ${ }^{[3]}$, Dorcas Lamounier Costa ${ }^{[4]}$ \\ and Carlos Henrique Nery Costa ${ }^{[4]}$
}

\begin{abstract}
[1]. Programa de Pós-Graduação em Ciência Animal, Centro de Ciências Agrárias, Universidade Federal do Piauí, Teresina, PI, Brasil. [2]. Departamento de Epidemiologia, Instituto de Medicina Social, Universidade do Estado do Rio de Janeiro, Rio de Janeiro, RJ, Brasil. [3]. Curso de Ciências Biológicas, Universidade Federal do Piauí, Floriano, PI, Brasil. [4]. Laboratório de Leishmanioses, Instituto de Doenças Tropicais "Natan Portella”, Universidade Federal do Piauí, Teresina, PI, Brasil.
\end{abstract}

\begin{abstract}
Introduction: The control of reservoirs for Leishmania infantum-induced zoonotic visceral leishmaniasis requires the identification of dogs posing a population risk. Here, we assessed the performance of several assays to identify Lutzomyia longipalpis infectious dogs. Methods: We evaluated 99 dogs that were positive for visceral leishmaniasis based on parasite identification. Serological analyses were performed using an enzyme-linked immunosorbent assay, immunofluorescence antibody tests in 1:40 and 1:80 dilutions, rapid dual path platform tests, immunochromatographic assay with a recombinant rK39 antigen, fast agglutination screening tests, and direct agglutination tests. We also performed PCR to analyze peripheral blood and xenodiagnosis. Results: Forty-six dogs infected at least one L. longipalpis specimen. Although the serological test sensitivities were above $85 \%$ for detecting L. longipalpis infectious dogs, none showed a satisfactory performance, as both specificity $(0.06$ to $13 \%$ ) and the area under the receiver operating characteristic curve (45 to 53\%) were low. The PCR results were also weak, with a sensitivity of $30 \%$, specificity of $72 \%$, and an area under the receiver operating characteristic curve of $51 \%$. The infected L. longipalpis proportion was higher among asymptomatic dogs than symptomatic dogs. Among the symptomatic dogs, those with ulceration-free skin diseases were more infectious, with an odds ratio of 9.3 (confidence interval of 1.10 - 428.5). The larger the number of insects fed, the greater the detected infectiousness. Conclusions: Our study supports the imperative to develop novel technologies for identifying the infectious dogs that transmit $L$. infantum for the benefit of public health.
\end{abstract}

Keywords: Visceral leishmaniasis. Leishmania infantum. Lutzomyia longipalpis.

\section{INTRODUCTION}

Visceral leishmaniasis (VL), also known as kala-azar, is responsible for approximately 60 thousand deaths yearly worldwide. The Phlebotominae sub-family of sandflies transmit $\mathrm{VL}^{1}$, with an estimated 200,000 to 400,000 new victims each year ${ }^{2}$. Lutzomyia longipalpis sandflies transmit the protozoa Leishmania infantum to spread the zoonotic form of VL across Central Asia, the Middle East, the Caucasus and Mediterranean regions, West Africa, and the Americas ${ }^{3,4}$. The main L. infantum reservoirs are wild dogs, marsupials, the domestic dog, and humans ${ }^{5-7}$.

Zoonotic VL most commonly occurs in Brazil. Moreover, Brazil likely has the only zoonotic VL transmission control

Corresponding author: Prof. Carlos Henrique Nery Costa.

e-mail: chncosta@gmail.com

Received 26 April 2017

Accepted 10 August 2017 program, which is based on the use of insecticide and culling infected $\operatorname{dogs}^{8,9}$. However, a systematic review of the use of these strategies, especially the canine reservoir control program, has revealed little if any impact on the prevalence of zoonotic $\mathrm{VL}^{10}$. Notably, these programs have not been successful in limiting the urbanization and territorial expansion of the disease in Brazil after more than 30 years of implementation and despite the efforts of sanitation authorities ${ }^{11,12}$.

The failure of the canine reservoir control program is in part due to its inability to correctly identify infected $\operatorname{dogs} s^{10,13}$. Serosurveys have been performed in areas with a low zoonotic VL prevalence; thus, many non-infected dogs have been culled. Moreover, many infected dogs remain in communities with a high zoonotic VL prevalence. The acknowledgment of such flaws has led some to question the program on both economic and moral grounds ${ }^{14,15}$. Methods to precisely identify not only the infected animals but also those that represent a greater risk of transmitting $L$. infantum to the vector L. longipalpis are needed immediately. 


\section{METHODS}

\section{Animals}

The present study involved 99 domestic dogs (58 males and 41 females) of different breeds and ages who were parasitologically confirmed for canine visceral leishmaniasis (CVL) and diagnosed at the Animal Sanity Laboratory at the Federal University of Piauí (UFPI) in Brazil. After a clinical evaluation, the dogs were administered CVL diagnostic exams. None of the dogs were serologically screened, but all were destined to be culled.

\section{Ethical considerations}

The study was approved by Ethics Committee on Animal Experimentation at the UFPI, under review number 053/2008.

\section{Clinical evaluation and sample collection}

All dogs were submitted to careful clinical evaluation from a veterinary doctor and diagnosed as symptomatic or asymptomatic. Dogs were considered symptomatic if they had at least one clinical sign suggestive of CVL, while asymptomatic dogs appeared completely healthy at the clinical examination. Skin features such as periocular and generalized alopecia, hair loss, seborrhea, and depigmentation in the muzzle were recorded to note the presence of skin disease without ulceration. Afterward, $10 \mathrm{~mL}$ of blood was collected from the jugular vein for serology and $40 \mu \mathrm{L}$ of blood was collected from the ear onto filter paper for deoxyribonucleic acid (DNA) extraction. To obtain samples for parasitological examination, bone marrow and popliteous lymph node aspiration were performed, in addition to scraping healthy skin or lesions in the ear or muzzle. The samples were dyed with Giemsa and observed at 100x magnification to visualize parasite amastigote forms. After confirming the infection, the dogs were humanely sacrificed and an aspiration puncture of the liver and spleen were performed. Culling was performed using an endovenous administration of a combination of ketamine, acepromazine, and diazepan. After 15 minutes of sedation, $20 \mathrm{~mL}$ of $10 \%$ potassium chloride was administered endovenously.

Bone marrow, popliteous lymph node, liver, and spleen samples were cultured in NNN medium enriched with Schneider medium (Sigma-Aldrich, St Louis, MI, USA) and incubated at $26^{\circ} \mathrm{C}$ in a low-temperature biological oxygen demand (BOD) refrigerated incubator. Every 5 days, the cultures were examined under a microscope at 40x to control the Leishmania promastigote forms, repeating this procedure until the 30 th incubation day or until a positive result was obtained. The cultures were considered negative after one month of testing.

\section{Diagnostic tests}

As previously reported ${ }^{16}$, we performed an enzyme-linked immunosorbent assay (ELISA), immunofluorescence antibody tests in 1:40 and 1:80 dilutions (IFAT40 and IFAT80), rapid dual path platform tests (RT-DPP), immunochromatographic assay with a recombinant rK39 antigen (ICrK39), fast agglutination screening tests (FAST), and direct agglutination tests (DAT), and polymerase chain reaction (PCR).

\section{Infectiousness evaluation}

To study infectiousness, a xenodiagnosis was performed with dogs that were sedated using $0.2 \%$ acepromazine. L. longipalpis females were obtained from a sandfly replenished colony that was initially established in 1995. First generation L. longipalpis females were kept at $26^{\circ} \mathrm{C}$ and $92 \%$ humidity, used five days after completely hatching, and deprived of any food source. Sixteen to 120 L. longipalpis females per dog were used, with a mean of 55 and median of 60 sandflies per animal. The sandflies were placed inside darkened plastic boxes with an approximate $12 \mathrm{~cm}$ diameter and $5 \mathrm{~cm}$ height. The boxes were open on one side, covered with organza tissue, and placed over the internal ear skin for $45 \mathrm{~min}$. The xenodiagnosis was performed after 4:00pm.

Next, the insects were placed inside a BOD incubator with cotton embedded in a $50 \%$ sugar solution. After the fifth day of blood repast, the females were dissected on sterile slides for promastigote count under 40x magnification.

\section{Statistical analysis}

To verify the accuracy of the tests that identified the dogs that were infectious to the vector, we calculated sensitivity, specificity, and the area under the receiver operating characteristic (ROC) curve for each test and the respective $95 \%$ confidence intervals. A Fisher's exact test was performed to evaluate the possible relationship between the results of xenodiagnoses, as a dichotomic variable (positive and negative), and symptomatology, also as a dichotomic variable (symptomatic and asymptomatic). To analyze of the proportion of infected insects in the asymptomatic and symptomatic groups, a chi-square test was performed. The association between clinical signs and vector infectiousness was also evaluated by calculating the odds ratios (using univariate and multivariate analyses) and the Cornfield approximation 95\% confidence interval. All analyses were conducted using the statistical package Stata ${ }^{\circledR}$ (College Station, TX, USA).

\section{RESULTS}

All tests diagnosing infectiousness performed poorly. Very low areas under the ROC curve were found, i.e., 53\% for FAST, $51 \%$ for ICrK39 and PCR, 50\% for RT-DPP, $48 \%$ for IFAT40 and ELISA, $46 \%$ for DAT, and $45 \%$ for IFAT 180 . Sensitivity was $98 \%$ for RT-DPP, 96\% for FAST, 93\% for IFAT $40,91 \%$ for DAT, $89 \%$ for ICrK39 and ELISA, and $67 \%$ for PCR. Most dogs with negative xenodiagnosis had reagent tests, which led to very low specificity (the highest value for PCRsp (28\%); Table 1).

Of the 99 dogs investigated, 88 were symptomatic and 11 were completely asymptomatic. Xenodiagnosis identified 46 dogs that infected at least one L. longipalpis specimen. Of the symptomatic dogs, $39(44 \%)$ had a positive xenodiagnosis result, while seven (64\%) asymptomatic dogs transmitted to the vector; however, this difference was not statistically significant $(p$-value $=0.34$, Fisher's exact test; Table 2).

The proportion of infected sandflies among all 2,646 examined was $5.8 \%$. The proportion was higher among those that fed on an asymptomatic dog (17.6\%) compared to those 
TABLE 1

Sensitivity, specificity, and the area under the receiver operating characteristic curve for xenodiagnosis of canine visceral leishmaniasis in an endemic region.

\begin{tabular}{|c|c|c|c|}
\hline Tests & $\begin{array}{l}\text { Sensitivity (\%) } \\
(95 \% \mathrm{CI})^{\mathrm{a}}\end{array}$ & $\begin{array}{l}\text { Specificity (\%) } \\
\quad(95 \% \text { CI) }\end{array}$ & $\begin{array}{l}\text { Area under the ROC curve (\%) } \\
\qquad(95 \% \mathrm{CI})\end{array}$ \\
\hline IFAT $40^{\mathbf{b}}$ & $93(86-100.0)$ & $2(0-6.0)$ & $47(44-52.0)$ \\
\hline $\mathrm{DAT}^{\mathbf{d}}$ & $91(83-100.0)$ & $0(0-0.0)$ & $46(42-50.0)$ \\
\hline $\mathrm{FAST}^{\mathbf{e}}$ & $96(90-100.0)$ & $9(1-18.0)$ & $53(48-58.0)$ \\
\hline RT DPP®g & $98(93-100.0)$ & $2(0-6.0)$ & $50(47-53.0)$ \\
\hline ELISA $^{\mathbf{h}}$ & $89(80-98.0)$ & $8(0-15.0)$ & $48(43-54.0)$ \\
\hline PCRsp $^{\mathbf{i}}$ & $30(17-44.0)$ & $72(17-59.0)$ & $51(42-60.0)$ \\
\hline
\end{tabular}

a95\% confidence interval. ${ }^{\mathbf{b}}$ indirect immunofluorescence reaction in a 1:40 dilution. ${ }^{\mathbf{c}}$ indirect immunofluorescence reaction in a 1:80 dilution.

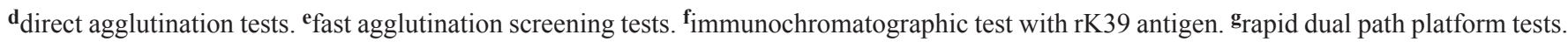
$\mathbf{h}_{\text {enzyme-linked immunosorbent assay. }}{ }^{\text {p }}$ eripheral blood polymerase chain reaction.

\section{TABLE 2}

Number and proportion of infected dogs with a positive xenodiagnosis result and the number and proportion of infected insects among all the insects examined in the asymptomatic and symptomatic groups.

\begin{tabular}{lcccc}
\hline Symptomatology & $\begin{array}{c}\text { Infected } \\
\text { dogs }\end{array}$ & $\begin{array}{c}\text { Number and proportion of animals with } \\
\text { positive xenodiagnosis (\%) }\end{array}$ & $\begin{array}{c}\text { Number of examined } \\
\text { insects }\end{array}$ & $\begin{array}{c}\text { Number and proportion of } \\
\text { infected insects (\%) }\end{array}$ \\
\hline Asymptomatic & 11 & $7(63.6)$ & 267 & $47(17.6)$ \\
Symptomatic & 88 & $39(44.3)$ & 2,379 & $106(4.5)$ \\
\hline All & 99 & $46(46.5)$ & 2,646 & $153(5.8)$ \\
\hline
\end{tabular}

${ }^{*} p$-value $=0.34$, Fisher's exact test. ${ }^{*} p$-value $=0.00$, chi-square test.

that fed on a symptomatic $\operatorname{dog}(4.5 \% ;$-value $=0.00$, chi-square test; Table 2).

Of all the annotated clinical signs, only skin disease without ulceration was significantly associated with the likelihood of infectiousness in dogs (i.e., infecting at least one sandfly), with an odds ratio of 9.3 (1.10 - 428.5 confidence interval; Table 3). Additionally, in the multivariate analysis, skin disease without ulceration was significantly associated with infectiousness to the vector (Table 3).

Mortality until insect dissection was $49.8 \%$ and ranged from 4 to $100 \%$, with a mean of 26.7 and a median of 25 dissected insects per dog that ranged from 3 to 81 . The greater the number of insects used or dissected insects for xenodiagnoses, the greater the chance of at least one being infected; Table 4).

\section{DISCUSSION}

For almost 30 years, serological tests for CVL diagnosis have been used extensively for disease control programs in Brazil years ${ }^{17}$. These tests are antibody-based and do not effectively distinguish infected dogs from healthy dogs with an immunological memory of a previous infection, as we have previously shown ${ }^{16,18}$. Therefore, a large number of seropositive, not infective dogs have been culled in Brazil. This policy has high economical and moral costs, now facing increasing community resistance due to its inefficiency ${ }^{10,19,20}$. In addition, dogs correctly found infected may not be actually infective to sandflies and place no risk for the population.

Studies inconsistently report the proportion of dogs with VL that are infectious to the vector L. longipalpis. In Brazil, Deane and Deane ${ }^{21}$ observed that $75 \%$ of 16 dogs transmitted L. infantum to $24.8 \%$ of 238 L. longipalpis specimens, with a mean of 14.9 insects per dog. Sherlock ${ }^{22}$ found that $65 \%$ of 20 dogs infected $29 \%$ of 368 L. longipalpis specimens, with a mean of 18.4 insects per dog. In Europe, Rioux et al..$^{23}$ reported having infected all 17 Phlebotomus ariasi that fed on a sick dog. Molina et al..$^{24}$ in Spain found that 13/16 dogs were infectious for Phlebotomus perniciosus, with only three dogs infecting over $70 \%$ of the sandflies evaluated. Differences in the infectiousness rate could have been due to a number of parasites acquired after an infectious repast (which depends on the infectiousness level of the dog), the type of maintenance diet sugars in the laboratory after repast ${ }^{25}$, temperature and humidity conditions, the sandfly species, and mainly, the time elapsed until dissection ${ }^{26}$. As a 
TABLE 3

Symptoms associated with dog infectiousness to Lutzomyia longipalpis.

\begin{tabular}{|c|c|c|c|c|}
\hline Clinical signs & $\begin{array}{c}\text { Odds ratio } \\
\text { (univariate analysis) }\end{array}$ & $\begin{array}{l}95 \% \text { confidence } \\
\text { interval }\end{array}$ & $\begin{array}{c}\text { Odds ratio } \\
\text { (multivariate } \\
\text { analysis) }\end{array}$ & $\begin{array}{l}95 \% \text { confidence } \\
\text { interval }\end{array}$ \\
\hline Snout lesion & 0.4 & $0.15-1.20$ & 0.3 & $0.07-1.09$ \\
\hline Apathy & 6.3 & $0.70-305.5$ & 2.1 & $0.10-44.3$ \\
\hline Lymphadenomegaly & 0.7 & $0.90-3.70$ & 0.1 & $0.01-1.50$ \\
\hline Snout depigmentation & 0.5 & $0.13-1.90$ & 0.6 & $0.15-2.90$ \\
\hline Lip lesion & 0.7 & $0.06-7.00$ & 2.7 & $0.34-22.3$ \\
\hline Thinnes & 1.3 & $0.40-4.20$ & 0.7 & $0.17-3.10$ \\
\hline Cachexia & 3.7 & $0.30-197.7$ & 5.0 & $0.06-461.8$ \\
\hline Body lesions & 1.2 & $0.30-4.80$ & 0.9 & $0.19-4.43$ \\
\hline Conjunctivitis & 0.4 & $0.04-2.80$ & 0.1 & $0.00-1.01$ \\
\hline Pale mucous tissues & 2.4 & $0.12-142.0$ & 20.9 & $0.27-1617.1$ \\
\hline Cornea opacity & 1.1 & $0.08-16.5$ & 0.01 & $0.00-1.85$ \\
\hline Epistaxis & 2.4 & $0.12-142.0$ & 5.7 & $0.17-196.5$ \\
\hline
\end{tabular}

TABLE 4

Effect of increasing the number of Lutzomyia longipalpis females examined or used in xenodiagnosis under the presence of at least one infected female (positive xenodiagnosis).

\begin{tabular}{|c|c|c|c|}
\hline $\begin{array}{l}\text { Number of used } \\
\text { Lutzomyia } \\
\text { longipalpis }\end{array}$ & $\begin{array}{c}\text { Number of positive xenodiagnosis/no. of } \\
\text { xenodiagnosis dogs }(\%)\end{array}$ & $\begin{array}{l}\text { Number of examined } \\
\text { Lutzomyia longipalpis }\end{array}$ & $\begin{array}{c}\text { Number of positive xenodiagnosis/no. of } \\
\text { examined dogs }(\%)\end{array}$ \\
\hline$\geq 10$ & $46 / 99(46.5)$ & $\geq 1$ & $46 / 99(46.5)$ \\
\hline$\geq 20$ & $45 / 98(45.9)$ & $\geq 5$ & $44 / 96(45.8)$ \\
\hline$\geq 30$ & $45 / 95(47.9)$ & $\geq 10$ & $40 / 88(45.5)$ \\
\hline$\geq 50$ & $35 / 70(50.0)$ & $\geq 30$ & $18 / 37(48.7)$ \\
\hline$\geq 60$ & $30 / 62(48.4)$ & $\geq 40$ & $9 / 18(50.0)$ \\
\hline$\geq 70$ & $5 / 6(83.3)$ & $\geq 50$ & $5 / 7(71.4)$ \\
\hline$\geq 80$ & $3 / 3(100.0)$ & $\geq 60$ & $2 / 2(100.0)$ \\
\hline
\end{tabular}


result, insects with a high infectiousness load may have died before being examined, while insects that acquired milder infections could have survived until the dissection day. However, this possibility is unlikely due to the short period ( 5 to 6 days) between feeding on the dogs and insect examination, as there was not enough time for the sandflies to develop high infection loads.

The present study was most concerned with whether every infected dog is actually infectious. From this perspective, infectiousness would depend on a high infectiousness load above a certain threshold in the insects used for xenodiagnosis, as our study suggested when a high number of insects were examined. Our study was not conclusive because only a small number of xenodiagnostic examinations were performed using a high number of insects. Nonetheless, under natural conditions, animals may be exposed to a high number of L. longipalpis bites when they are infectious; therefore, all infected dogs may indeed be infectious to some degree and for some period time, depending on an exposure to a critical amount of sandflies. Notably, xenodiagnostic studies ${ }^{21,27}$ have shown that some more infectious animals can be discriminated, while less infectious animals cannot. However, transmission is an exponential function depending on vector daily mortality ${ }^{28}$, which is high, from 15 to $20 \%{ }^{29}$; thus, poorly infectious dogs may not contribute to transmission. These studies suggest that diagnostic tests can distinguish more infectious dogs, which are the actual sources of infection under natural conditions, from less infectious or non-infectious dogs. An elegant study in Ethiopia showed that in fact only a few individuals contribute to transmission ${ }^{30}$. A control program that discriminates infectiousness would identify such animals.

Our study showed that no test could be used to discriminate infectious dogs from those that were previously infected. These serological tests identify antibodies but not parasites, although antibody titers may be related to infectiousness ${ }^{31}$. Our results show that only ICrK39 and FAST could indicate infectiousness. RT-DPP and ELISA, which are used in the Brazilian VL control program $^{32}$, were unable to discriminate the most infectious dogs. Negative DAT, FAST, and ICrK39 results can be used to distinguish some portion of the most infectious dogs, but a significant proportion of these animals will remain in the community. Consequently, although some diagnostic tests can reveal the infectiousness status of the dog population, they are unable to distinguish the infected dogs that actually represent a population risk.

Serological tests cannot be used to indicate infectiousness because they only measure antibodies. PCR could be more useful in this regard. However, PCR yielded some of the worse results. We analyzed only a very small volume of blood, equivalent to what 20 sandflies inges ${ }^{33}$; thus, our approach may explain our results. As a result, with a low circulating parasite density ${ }^{34}$, PCR and xenodiagnosis would discriminate different animals, as skin but not blood appears to be the main source of L. infantum transmission to vectors ${ }^{35}$.

In our study, asymptomatic dogs had a greater probability of infecting $L$. longipalpis than symptomatic dogs, making the correct identification of dogs representing a population risk even more difficult, although the literature is conflicting ${ }^{31,36-40}$. In contrast, dogs with dermatitis were much more infectious, and this feature was the only clinical sign that had any discriminatory value. Although dermatitis is a low-frequency clinical sign, this information could be useful given the difficulty of identifying infectiousness-related signs. Quantitative buffy coat ${ }^{41}$ and molecular tests ${ }^{40}$ are potentially useful approaches to identify infectious dogs, as they can directly identify circulating parasites. However, given that VL transmission from dogs likely occurs via the $\operatorname{skin}^{39,40,42}$, new approaches to identify infectiousness should focus on skin rather than blood samples.

Vertebrate host infectiousness data vary widely, indicating that this elusive information is unstable, uncertain, complex, and dependent on multivariate factors. In addition, directly measuring infectiousness based on xenodiagnosis is complex, limiting its use on a large scale and for long periods of time. Therefore, to better correctly identify infectious individuals, as we attempted, further investigation is necessary. Such experiments should focus on identifying and controlling the variables that determine the complexity of infectiousness and the development of simple technological alternatives to xenodiagnosis. Until then, the present investigation and any similar future studies will only substantiate the fact that the available methods are inefficient.

\section{Conflict of interest}

The authors declare that there is no conflict of interest.

\section{REFERENCES}

1. Desjeux P. Leishmaniasis: current situation and new perspectives. Comp Immunol Microbiol Infect Dis. 2004;27(5):305-18.

2. Alvar J, Velez ID, Bern C, Herrero M, Desjeux P, Cano J, et al. Leishmaniasis worldwide and global estimates of its incidence. Plos One. 2012;7(5):e35671.

3. World Health Organization (WHO). Control of the Leishmaniases. Report of a WHO Expert Commitee. World Health Organization Tech Rep Ser. 1990;793:1-158.

4. Maurício IL, Stothard JR, Miles MA. The strange case of Leishmania chagasi. Parasitol Today. 2000;16(5):188-9.

5. Deane LM. Leishmaniose visceral no Brasil: estudos sobre reservatórios e transmissores realizados no Estado do Ceará. 1th edition. Rio de Janeiro: Serviço Nacional de Educação Sanitária; 1956. $162 \mathrm{p}$.

6. Hanson WL, Chapman Jr WL, Hendricks LD. Leishmania donovani in the oppossum (Didelphis marsupialis). J Parasitol. 1980;66(4):700-1.

7. Silveira FT, Lainson R, Shaw JJ, Povoa MM. Leishmaniasis in Brazil: XVIII. Further evidence incriminating the fox Cerdocyon thous (L) as a reservoir of Amazonian visceral leishmaniasis. Trans R Soc Trop Med Hyg. 1982;76(6):830-2.

8. Lacerda MM. The Brazilian Leishmaniasis Control Program. Mem Inst Oswaldo Cruz. 1994;89(3):489-95.

9. Ministério da Saúde. Manual de Vigilância e Controle da Leishmaniose Visceral. 1th edition. Brasília: Editora do Ministério da Saúde; 2014. 120 p. 
10. Romero GA, Boelaert M. Control of visceral leishmaniasis in Latin America: a systematic review. PLoS Neg1 Trop Dis. 2010;4(1):e584.

11. Costa CHN. Characterization and speculations on the urbanization of visceral leishmaniasis in Brazil. Cad Saúde Pública. 2008;24(12):2959-63.

12. Maia-Elkhoury AN, Alves WA, Sousa-Gomes ML, Sena JM, Luna EA. Visceral leishmaniasis in Brazil: trends and challenges. Cad Saúde Pública. 2008;24(12):2941-7.

13. Costa $\mathrm{CH}$, Vieira JB. Mudanças no controle da leishmaniose visceral no Brasil. Rev Soc Bras Med Trop. 2001;34(2):223-8.

14. Costa $\mathrm{CH}$. How effective is dog culling in controlling zoonotic visceral leishmaniasis? A critical evaluation of the science, politics and ethics behind this public health policy. Rev Soc Bras Med Trop. 2011;44(2):232-42.

15. Machado CJS, Silva EG, Vilani RM. O uso de um instrumento de política de saúde pública controverso: a eutanásia de cães contaminados por leishmaniose no Brasil. Saude Soc. 2016;25(1):247-58.

16. Mendonça IL, Batista JF, . The performance of serological tests for Leishmania infantum infection screening in dogs depends on the prevalence of disease. Rev Inst Med Trop São Paulo. 2017;59:e39.

17. Ministério da Saúde. Manual de Vigilância e Controle da Leishmaniose Visceral. 1th edition. Brasília: Editora do Ministério da Saúde; 2004. 120 p.

18. Dye C, Vidor E, Dereure J. Serological diagnosis of leishmaniasis: on detecting infection as well as disease. Epidemiol Infect. 1993;110(3):647-56.

19. Ashford DA, Bozza M, Freire M, Miranda JC, Sherlock I, Eulalio $\mathrm{C}$, et al. Comparison of the polymerase chain reaction and serology for the detection of canine visceral leishmaniasis. Am J Trop Med Hyg. 1995;53(3):251-5.

20. Moreno J, Alvar J. Canine leishmaniasis: epidemiological risk and the experimental model. Trends Parasitol. 2002;18(9):399-405.

21. Deane LM, Deane MP. Visceral leishmaniasis in Brazil: geographical distribution and transmission. Rev Inst Med Trop Sao Paulo. 1962;4:198-212.

22. Sherlock IA. Ecological interactions of visceral leishmaniasis in the State of Bahia, Brazil. Mem Inst Oswaldo Cruz. 1996;91(6):671-83.

23. Rioux JA, Killick-Kendrick R, Leaney AJ, Young CJ, Turner DP, Lanotte G, et al. Ecology of leishmaniasis in the south of France. 11. Canine leishmaniasis: successful experimental transmission from dog to dog by the bite of Phlebotomus ariasi Tonnoir, 1921 (author's transl). Ann Parasitol Hum Comp. 1979;54(4):401-7.

24. Molina R, Amela C, Nieto J, San-Andrés M, González F, Castillo $\mathrm{JA}$, et al. Infectivity of dogs naturally infected with Leishmania infantum to colonized Phlebotomus perniciosus. Trans R Soc Trop Med Hyg. 1994;88(4):491-3.

25. Schlein Y. Sandfly diet and Leishmania. Parasitol Today. 1986;2(6):175-7.

26. Lainson R, Ward RD, Shaw JJ. Experimental transmission of Leishmania chagasi, causative agent of neotropical visceral leishmaniasis, by the sandfly Lutzomyia longipalpis. Nature. 1977;266(5603):628-30

27. Quinnell RJ, Dye C, Shaw JJ. Host preferences of the phlebotomine sandfly Lutzomyia longipalpis in Amazonian Brazil. Med Vet Entomol. 1992;6(3):195-200.
28. Dye C. Leishmaniasis epidemiology: the theory catches up. Parasitolology. 1992;104(Suppl):S7-18.

29. Ferro C, Morrison AC, Torres M, Pardo R, Wilson ML, Tesh RB. Age structure, blood-feeding behavior, and Leishmania chagasi infection in Lutzomyia longipalpis (Diptera: Psychodidae) at an endemic focus of visceral leishmaniasis in Colombia. J Med Entomol. 1995;32(5):618-29.

30. Miller E, Warburg A, Novikov I, Hailu A, Volf P, Seblova V, et al. Quantifying the contribution of hosts with different parasite concentrations to the transmission of visceral leishmaniasis in Ethiopia. PLoS Neg1 Trop Dis. 2014;8(10):e3288

31. Laurenti MD, Rossi CN, da Matta VL, Tomokane TY, Corbett CE, Secundino NF, et al. Asymptomatic dogs are highly competent to transmit Leishmania (Leishmania) infantum chagasi to the natural vector. Vet Parasitol. 2013;196(3-4):296-300.

32. Oliveira AC, Figueiredo FB, Silva VL, Santos FN, Sousa MB, Madeira MF, et al. Canine visceral leishmaniasis case investigation in the Jacare region of Niteroi, Rio de Janeiro, Brazil. Rev Inst Med Trop São Paulo. 2015;57(4):325-32.

33. Ready PD. Factors affecting egg production of laboratory-bred Lutzomyia longipalpis (Diptera: Psychodidae). J Med Entomol. 1979;16(5):413-23.

34. Rohrs LC. Leishmaniasis in the Sudan Republic. XVIII. Parasitemia in Kala-Azar. Am J Trop Med Hyg. 1964;13:265-71.

35. Silva JC, Zacarias DA, Silva VC, Rolão N, Costa DL, Costa CHN. Comparison of optical microscopy and quantitative polymerase chain reaction for estimating parasitaemia in patients with kala-azar and modelling infectiousness to the vector Lutzomyia longipalpis. Mem Inst Oswaldo Cruz. 2016;111(8):517-22.

36. Courtenay O, Quinnell RJ, Garcez LM, Shaw JJ, Dye C. Infectiousness in a cohort of brazilian dogs: why culling fails to control visceral leishmaniasis in areas of high transmission. J Infect Dis. 2002;186(9):1314-20.

37. Travi BL, Ferro C, Cadena H, Montoya-Lerma J, Adler GH. Canine visceral leishmaniasis: dog infectivity to sand flies from nonendemic areas. Res Vet Sci. 2002;72(1):83-6.

38. Michalsky EM, Rocha MF, da Rocha Lima AC, França-Silva JC, Pires MQ, Oliveira FS, et al. Infectivity of seropositive dogs, showing different clinical forms of leishmaniasis, to Lutzomyia longipalpis phlebotomine sand flies. Vet Parasitol. 2007;147(1-2): 67-76.

39. Verçosa BL, Lemos CM, Mendonca IL, Silva SM, de Carvalho SM, Goto $\mathrm{H}$, et al. Transmission potential, skin inflammatory response, and parasitism of symptomatic and asymptomatic dogs with visceral leishmaniasis. BMC Vet Res. 2008;4(45):1-7.

40. Courtenay O, Carson C, Calvo-Bado L, Garcez LM, Quinnell RJ. Heterogeneities in Leishmania infantum infection: using skin parasite burdens to identify highly infectious dogs. PLoS Negl Trop Dis. 2014;8(1):e2583.

41. Liarte DB, Mendonca IL, Luz FC, Abreu EA, Mello GW, Farias $\mathrm{TJ}$, et al. QBC for the diagnosis of human and canine american visceral leishmaniasis: preliminary data. Rev Soc Bras Med Trop. 2001;34(6):577-81

42. Saridomichelakis MN, Koutinas AF, Olivry T, Dunston SM, Farmaki R, Koutinas CK, et al. Regional parasite density in the skin of dogs with symptomatic canine leishmaniosis. Vet Dermatol. 2007;18(4):227-33. 